\title{
ALTERATIONS IN PLATELET ACTIVITY AND ELASTIC MODULUS OF HEALTHY SUBJECTS, CARRIERS OF G20210A POLYMORPHISM IN THE PROTHROMBIN GENE
}

\author{
Regina Komsa-Penkova, \\ Svetla J. Todinova', \\ Tonya D. Andreeva ${ }^{1}$, \\ Sashka B. Krumova', \\ Stefka G. Taneva ${ }^{1}$, \\ Georgi M. Golemanov, \\ Galia A. Georgieva, \\ Nikolina M. Mihaylova ${ }^{2}$, \\ Andrey I. Tchorbanov', \\ Pencho T. Tonchev ${ }^{3}$
}

Department of Biochemistry, Medical University - Pleven, Bulgaria ${ }^{1}$ Institute of Biophysics and Biomedical Engineering, Bulgarian Academy of Sciences ${ }^{2}$ Laboratory of Experimental Immunology, Institute of Microbiology, Bulgarian Academy of Sciences ${ }^{3}$ Department of Surgery, Medical University - Pleven, Bulgaria

Corresponding Author:

Regina Komsa-Penkova

Department of Biochemistry

Medical University - Pleven

1, St. Kl. Ohridski Str.

Pleven, 5800

Bulgaria

e-mail:rkomsa@gmail.com

Received: June 15, 2016

Revision received: June 24, 2016

Accepted: September 15, 2016

\section{Summary}

Platelet activation is a complex process in which platelet reorganization takes place associated with changes in the cell shape, topology, membrane elasticity and microparticle production. The aim of this study was to investigate the changes/aberrations in the platelet activity, elasticity and morphology in healthy subjects, carriers of A allele of prothrombin G20210A polymorphism. Blood samples from 18 healthy subjects were used for platelet analysis by force-mode atomic force microscopy. Restriction analysis was used to investigate the carriage of G20210A polymorphism in the prothrombin gene. Flowcytometry was applied to evaluate platelet activation. Young's modulus of the plasma membranes of platelets derived from healthy subjects, carriers of variant A allele of prothrombin $20210 \mathrm{G}>\mathrm{A}$ polymorphism $(407 \pm 69 \mathrm{kPa})$ is two times higher than the one determined for noncarriers $(195.4 \pm 48.7 \mathrm{kPa} ; \mathrm{p}<0.05)$. The background activity of platelets measured as an interrelation of Cd41/Cd61 and CD62 by flow cytometry was also higher in carriers of variant A allele of prothrombin $20210 \mathrm{G}>\mathrm{A}$ polymorphism $(5.0 \%)$ than in non-carriers $(1.3 \%)$. Platelets isolated from healthy carriers of variant A allele of prothrombin $20210 \mathrm{G}>\mathrm{A}$ polymorphism exhibited a higher level of activity and a higher degree of stiffness at the stage of spreading as compared to platelets from noncarriers.

Key words: platelet activity, elasticity modulus, G20210A polymorphism

\section{Introduction}

Platelet activation and spreading represent a multistep process resulting in reorganization of the platelet membrane, cytoskeleton, organelles, as well as a remarkable change in the platalets' shape, occurring at distinct morphological steps $[1,2]$. On activation, platelets undergo a remarkable shift from anucleate 2-5 $\mu \mathrm{m}$ discs to smaller spheres with extended actin-rich lamellae and filopodia [3]. Platelets possess particular nano-mechanical properties and might exhibit either viscous or elastic characteristics determined by the physical state of the cell membrane and other cell components [4]. The alterations in platelet topology and its impact on platelet activity phase/stage are affected by the environment and inheritable factors. The morphology and elasticity of platelets exert a strong 
effect on platelet activation and are vitally related to cell function $[5,6]$. Platelet adhesion and activation is a reversible process at its regulation involves activation of integrin $\alpha_{\mathrm{II}} \beta_{3}$, a process dependent on the generation of thrombin, adenosine diphosphate (ADP), and thromboxane $\mathrm{A}_{2}\left(\mathrm{TXA}_{2}\right)[7,8]$.

Thrombin concentration reflects various factors among which a genetic defect in the gene coding for prothrombin $20210 \mathrm{G}>\mathrm{A}$ polymorphism, that results in the production of prothrombin (hyperprothrombinemia) and thrombin at levels two times higher.

A substitution $20210 \mathrm{G}>\mathrm{A}$ in the $3^{\prime}$ untranslated region of the gene of prothrombin is a single nucleotide polymorphism (SNP) that causes increased pre-mRNA stability [9] and elevated level of plasma prothrombin. The carriers of A allele of the $20210 \mathrm{G}>\mathrm{A}$ polymorphism have an enhanced tendency to thrombosis $[10,11]$.

The changes produced by elevated concentration of thrombin at different stages of platelets activation could provide an important insight into the regulation of platelet morphology and function.

During the last decade, platelets and other cells have been actively investigated by atomic force microscopy (AFM) [12] to determine their topographical and biomechanical characteristics upon platelet activation $[13,14]$.

In this work we combined AFM and flowcytometry tools to evaluate the changes in platelet elasticity and activation in healthy subjects, carriers and non-carriers of variant $\mathrm{A}$ allele of prothrombin G20210A $>$ T polymorphism, and the influence of the protrombotic mutation.

\section{Materials and methods}

\section{Selection of subjects and study protocol}

The investigated group included 18 unrelated healthy Caucasian individuals with no family history of thrombosis. The healthy subjects, carriers of A allele of prothrombin $20210 \mathrm{G}>\mathrm{A}$ polymorphism were selected from a database of healthy controls and repeatedly investigated for the mutation carriage. The carriage of prothrombin $20210 \mathrm{G}>\mathrm{A}$ polymorphism in healthy controls is $2.8 \% \quad(p=0.0018)$. Eight carriers and ten non-carriers were included in the investigation.

\section{Data collection}

The baseline characteristics were taken from personal interviews, using a specially designed questionnaire (Table 1). Blood clotting parameters were determined by conventional techniques in routine use at the University Hospital.

The study protocol was approved by the ethics committee of the Medical University - Pleven. All the subjects included gave informed consent for the investigation.

Table 1. Basic data of the investigated subjects

\begin{tabular}{llll}
\hline Characteristics & Total & $\begin{array}{l}\text { Carriers of 20210A } \\
\text { polymorphism }\end{array}$ & $\begin{array}{l}\text { Non-carriers of 20210A } \\
\text { polymorphism }\end{array}$ \\
\hline Subjects $(\mathrm{n}, \%)$ & 18 & $8(44.4 \%)$ & $10(55.6 \%)$ \\
\hline Age $(\mathrm{years})$ & $42.9 \pm 12.27$ & $41.81 \pm 11.93$ & $43.78 \pm 13.06$ \\
\hline BMI $\left(\mathrm{kg} / \mathrm{m}^{2}\right)$ & 25.83 & 24.77 & 26.16 \\
\hline
\end{tabular}

\section{Sample collection for DNA analysis}

Venous blood was collected in vacutainers containing $0.0084 \mathrm{ml} \mathrm{15 \%}$ EDTA (Becton, Dickinson and Company). DNA was isolated according to the procedure of GFTTM Genomic Blood DNA Purification Kit (Amersham Pharmacy Biotech Inc.). DNA samples were quantified using the agarose gel procedure. Polymerase Chain Reaction (PCR) was carried out in a total volume of $20 \mu \mathrm{l}$ containing $1 \mu \mathrm{l}(100$ $\mathrm{ng} / \mu \mathrm{l})$ genomic DNA, $0.4 \mu \mathrm{l}(20 \mathrm{pmol} / \mu \mathrm{l})$, respectively, forward and reverse primers, $1.8 \mu 1$ $(5 \mathrm{mmol} / \mu \mathrm{l})$ deoxynucleotide triphosphates, $\mathrm{MgCl} 2.0 \mu \mathrm{l}(25 \mathrm{mmol} / \mu \mathrm{l}), 2.0 \mu \mathrm{l}$ Buffer for Taq polymerase, and Taq polymerase $1 \mathrm{U}$ per sample (AB gene).

The amplification was carried out by thermocycler (Techne, version 11.04). The 
primers and reaction conditions for the investigated genetic defects have been described in a previous work [15].

PCR products were fractionated by electrophoresis through $2.5 \%$ agarose (AppliChem) and visualized in UV light by ethidium bromide staining $(10 \mathrm{mg} / \mathrm{ml}, 10 \mu \mathrm{l})$.

The amplified samples $(10 \mu \mathrm{l})$ were incubated at $37^{\circ} \mathrm{C}$ for 12 hours with a specific enzymerestrictase (3U per sample) in the presence of 0.2 $\mu 1$ Bovine serum albumin (Purified BSA 10 $\mathrm{mg} / \mathrm{ml}$ - New England BioLabs Inc.), $2 \mu 1$ NEB Buffer 2 (New England BioLabs Inc.) in a total volume of $20 \mu \mathrm{l}$.

Hind III (20 $000 \mathrm{U} / \mathrm{ml})$ restrictase was used for each mutation (New England BioLabs Inc.).

The products of restrictase reaction were separated by electrophoresis over 3.5\% agarose gel and visualized in UV light by ethidium bromide staining $(10 \mathrm{mg} / \mathrm{ml}, 10 \mu \mathrm{l})$.

Guidelines to avoid PCR contamination were strictly followed [16].

\section{Sample collection for platelets analysis}

Samples of $10 \mathrm{ml}$ venous blood were obtained early in the morning from fasting individuals by means of the minimum tourniquet pressure method. The first $5 \mathrm{ml}$ in each sample were utilized for polymorphism analysis, while the rest of the sample was used for platelets. The procedures were performed with minimum mixing or agitation and at room temperature. Platelet-rich plasma (PRP) was obtained by centrifugation of whole blood at $1000 \mathrm{rpm}$ (150 g) for $15 \mathrm{~min}$ at room temperature. Then PRP was subjected to centrifugation at $2700 \mathrm{rpm}$ for $5 \mathrm{~min}$ that yielded a platelet-rich pellet. After gentle resuspension in phosphate-buffered saline (PBS buffer), the pellet was additionally washed twice in PBS buffer before performing the imaging experiments [17].

\section{Sample preparation for AFM imaging and force mapping}

The isolated platelets were spread on sterilized round glass slides. After $30 \mathrm{~min}$ incubation, the loosely attached cells were washed out with PBS buffer. The platelets were fixed with $2.5 \%$ glutaraldehyde for 40 minutes, washed again and dried under a nitrogen stream.

Contact mode AFM imaging in air was performed with NanoScopeV system (Bruker Inc.) [18]. Standard silicon nitride $\left(\mathrm{Si}_{3} \mathrm{~N}_{4}\right)$ probe tips (Budget Sensors, Innovative Solutions Ltd.,
Bulgaria) with tip radius $<10 \mathrm{~nm}$, scanning rate of $0.2 \mathrm{~Hz}$ and resolution of $512 \times 512$ pixels were used. The analysis was performed using Bruker NanoScope Analysis 1.3 software [19].

Force curves (recorded at $0.5 \mathrm{~Hz}, 128$ pixels) were recorded for an array of points on the cell surface and a three-dimensional array of force data was generated [20].

The elastic properties of the sample were described by Young's modulus (E) determined according to the Hertz model $[21,22]$.

\section{Flow cytometry}

Whole blood containing anticoagulant (3.2\% sodium citrate, BD Vacutainer) was diluted 1:10 in modified HT buffer - $10 \mathrm{mM}$ HEPES, $137 \mathrm{mM}$ $\mathrm{NaCl}, 2.8 \mathrm{mM} \mathrm{KCl}, 1 \mathrm{mM} \mathrm{MgCl}_{2}, 12 \mathrm{mM}$ $\mathrm{NaHCO}_{3}, 0.4 \mathrm{mM} \mathrm{Na}_{2} \mathrm{HPO}_{4}, 0.35 \%$ (w/v) BSA, $5.5 \mathrm{mM}$ glucose, $\mathrm{pH}$ 7.4. A three-color module with fluorescence-conjugated monoclonal antibodies was used in the study to investigate platelet activation. Diluted whole blood was incubated at room temperature with FITCconjugated mouse anti-human CD41 (clone MEM-06; EXBIO, Praha), APC-conjugated mouse anti-human CD61 (clone VIPL2; EXBIO, Praha) and with PE-conjugated mouse antihuman CD62P (clone AK-4; EXBIO, Praha). The incubation was discontinued after 30 minutes by adding $500 \mu \mathrm{L}$ of BD Cellfix ${ }^{\mathrm{TM}}$. Fifty thousand cells were analyzed from each sample with a BD LSR II flow cytometer using the Diva 6.1.1 software (BD Biosciences, San Jose, CA).

\section{Results}

\section{Young's modulus}

The Young's modulus is a measure of the elasticity of cell membranes. The Young's modulus was determined by fitting the equation to each force-distance curve and was expressed by relation of stress to strain. The force curves (about 15 force-distance curves for each image) were recorded from the central part of the platelets, presuming that the stiffness of the human platelets varies in different parts of the cell.

The Young's modulus of the platelets isolated from subjects carriers of variant A allele of prothrombin $20210 \mathrm{G}>\mathrm{A}$ polymorphism was significantly higher as compared to the control non-carriers - 407 $\pm 69 \mathrm{kPa}$ versus $195.4 \pm 48.7$ $\mathrm{kPa}$, respectively $(\mathrm{p}<0.05$; Figure 1$)$. 


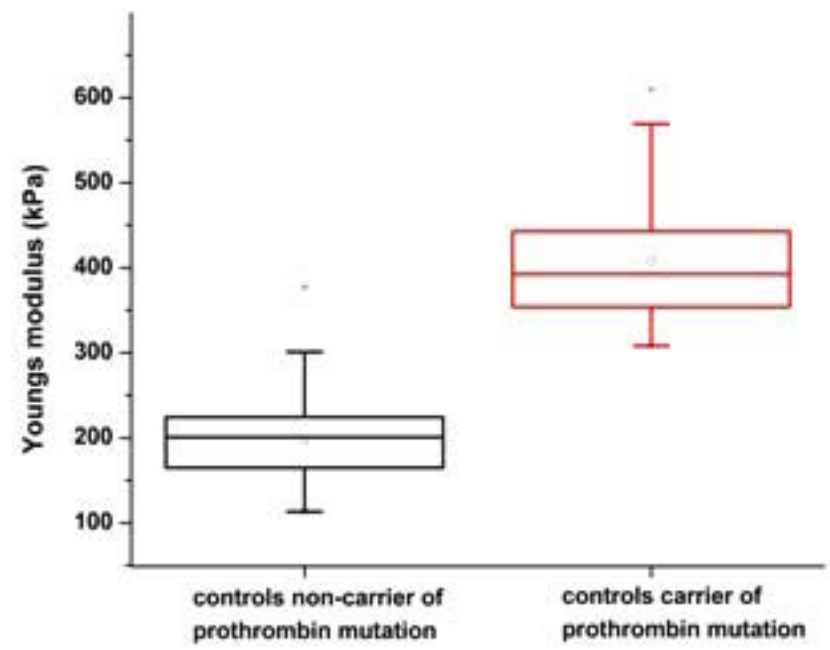

Figure 1. Box chart representation of Young's modulus determined for platelets obtained from healthy controls non-carriers of variant A allele of prothrombin G20210A mutation (black) and of carrier of pro-thrombotic mutation (red)

\section{Flow cytometry}

The samples explored by flow cytometry apparently contained a mixture of resting and activated platelets. The data was displayed using logarithmic-orthogonal and logarithmic-forward light scatter (Figure 2). The gated CD61-positive cells were sub-gated with CD41 and CD62P.

The double positive population CD41/CD62P
(Q2) was characterized as activated platelets. Activated platelets from healthy subjects, noncarriers of variant A allele of G20210A polymorphism were $1.3 \%$, while the CD62P positive platelets in healthy subjects, carriers of variant A allele of G20210A polymorphism accounted for $5 \%$ of the double positive population CD41/CD62P(Q2).

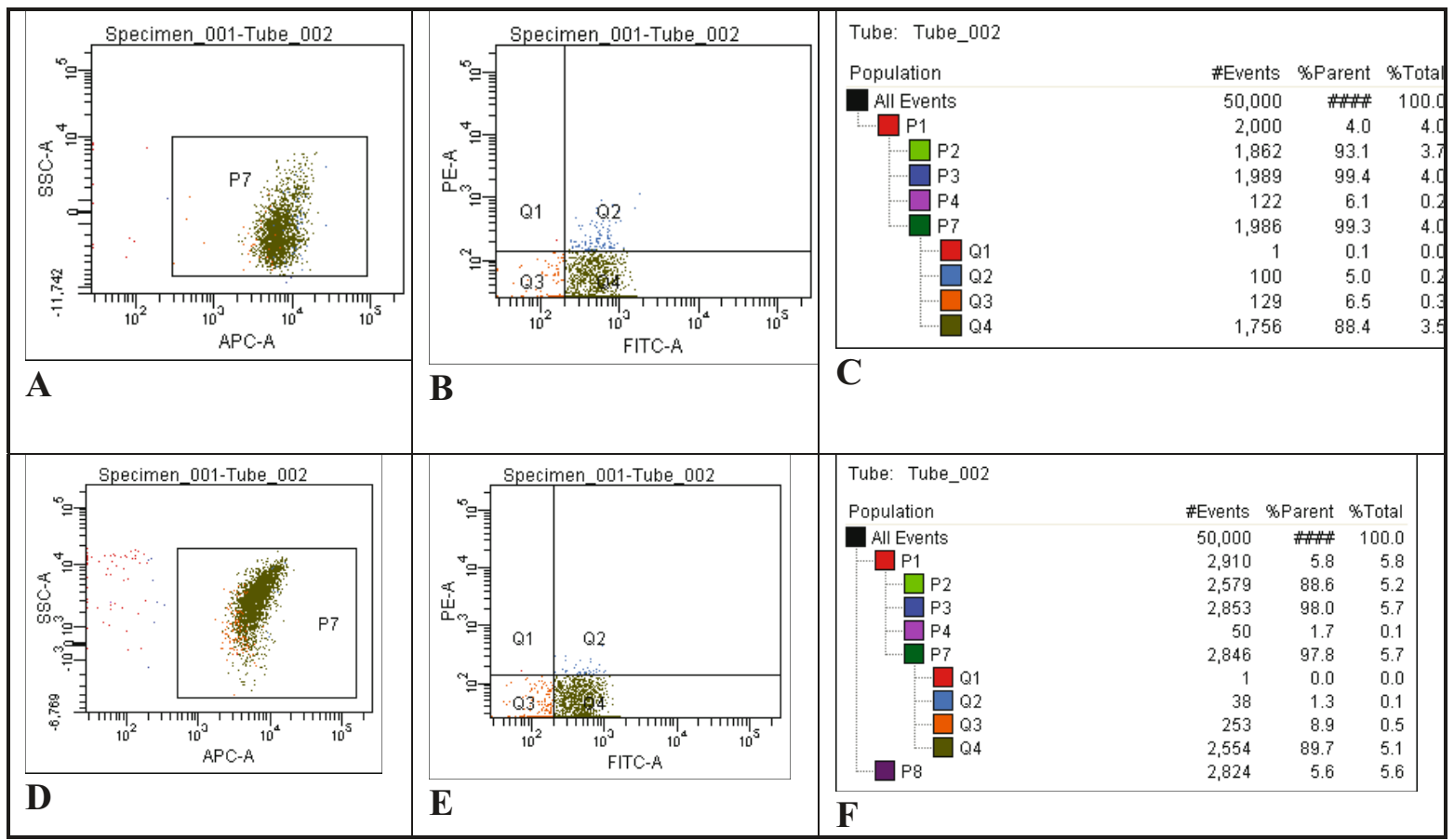

Figure 2. Flow-cytometry of the platelets isolated from healthy subjects. Scatterplots recorder of non-carriers (A, B , C) and carriers (D, E, F) of A allele of pro-thrombotic 20210A polymorphism. Platelets were labelled with anti-human CD41, FITC HIP8; Anti-Human CD61 (Integrin beta 3) APC (V); Anti-Human CD62P PE (AK-4), and activation was measured 


\section{AFM imaging of platelets from healthy subjects}

The objects of resting platelets observed by AFM
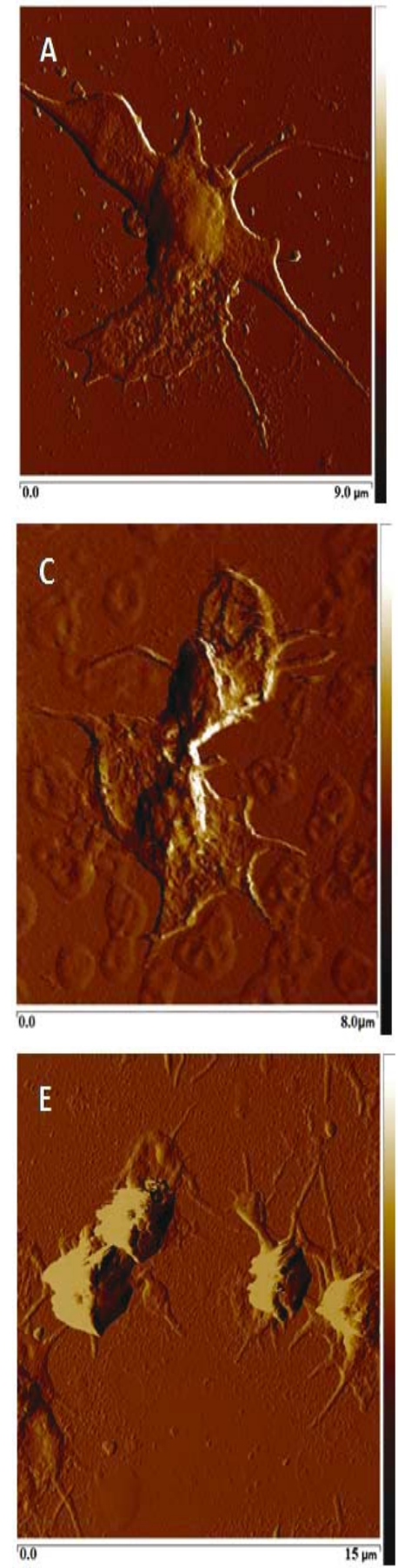

are rather few, as most of the platelets get activated after they come into contact with an artificial material, such as the glass coverslip
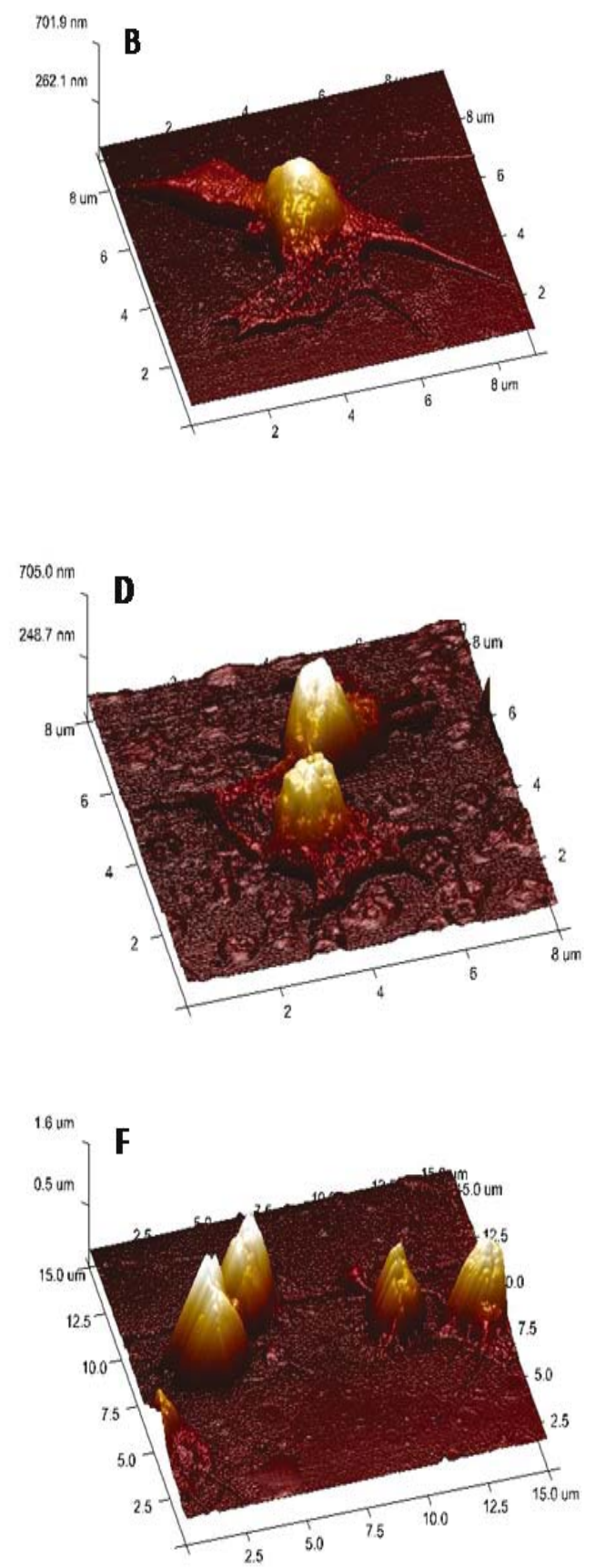

Figure 3. Representative AFM images of activated platelets derived from healthy subject, carrier of G20210A polymorphism, deposited onto glass coverslip. (A) AFM-2D profile with a shadowing effect of freshly prepared platelets derived from healthy individual non-carrier of variant A allele of prothrombin G20210A mutation (C) AFM-2D profile of freshly prepared platelets derived from healthy individual carrier of variant A allele of prothrombin G20210A mutation. (E) AFM-2D profiles of fresh platelets derived from the same individual (carrier of variant A allele of prothrombin G20210A polymorphism) in the presence of $\mathrm{Mg}^{2+}$ ions, (inhibition of aggregation). (B, D, F) AFM-3D topographical images of the corresponding platelets in images A, C and E. The platelets were fixed with $2.5 \%$ glutaraldehyde. The images were taken at room temperature in tapping mode in air 
support used in this study.

The morphological changes like membrane protrusions, filopodia/pseudopodia formation, and spreading on a surface were observed in samples from both carriers and non-carriers of 20210A polymorphism (Figure $3 \mathrm{~A}, \mathrm{~B}, \mathrm{C}$ and D). However, the activation state was more accelerated/advanced in carriers of prothrombin 20210A polymorphism. Platelets, derived from controls, carriers of 20210A polymorphism were completely spread over the glass coverslip with a negligible number of filopodia, unlike platelets of non-carriers. Moreover, the number of platelets-carriers of polymorphism per unit area was larger and they had a higher tendency to stick to each other. The addition of $\mathrm{Mg}^{2+}$ ions inhibited the aggregation process and slowed down the activation effect (Figure $3 \mathrm{~F}$ and $\mathrm{E}$ ). Although the tendency to stack retained, the hialoplazma was not spread. The initial protrusion of the pseudopodia could be observed as shown on Figure 3E.

\section{Discussion}

The aim of the study was to compare the changes in the topology and Young's modulus in platelets, isolated from healthy individuals, carriers and non-carriers of $20210 \mathrm{G}>\mathrm{A}$ polymorphism in a prothrombin gene and thus evaluate the impact of altered thrombin on platelet behaviour in healthy (non-diseased) condition.

Elasticity maps obtained from the platelets of the healthy carriers of $20210 \mathrm{G}>$ A polymorphism were characterized by a much higher value of Young's modulus than the corresponding modulus of the platelets from healthy noncarriers (Figure 1). The stiffness of the platelet membranes of the carriers was substantially (twice) and significantly higher than of those derived from the non-carriers $(p<0.05)$. Modulations in membrane stiffness have also been found by other authors investigating platelets topology and elasticity. It has been shown by Du Plooy et al. that stiffness of the platelets is a factor dependent on smoking status [23] as well as on the status of thrombosis. However, data on Young's modulus in thrombotic disease is controversial [24]. Our results from investigating patients with thrombosis (unpublished data) revealed elevated values of membrane elasticity in patients in acute events.

Young's modulus values, calculated for healthy subjects in our study were higher $(>180$ $\mathrm{kPa}$ ) than the ones reported by Lee and Marchant - 46.5, 29.7, and $6.2 \mathrm{kPa}$, respectively [13], and by Rheinlaender et al. (46.6 kPa) [2]. This could be attributed to the fact that the AFM measurements were done on platelets fixed with $1 \%$ glutaraldehyde in air and not in a fluid state.

The results regarding morphology of the cells, their shape, number of filopodia, lamelia and the number and shape of the microparticles (Figure 3 ) were also much more expressed in carriers than in non-carriers. The height of the platelets was higher in the carriers of $20210 \mathrm{G}>\mathrm{A}$ as well (Table 2). In the presence of $\mathrm{Mg}^{2+}$ (inhibitor of activation) these effects were reduced. The data from flow cytometry provided the additional evidence of higher level of platelets activation in the carriers of A allele of G20210A polymorphism, though not leading to a pathological event.

Based on the atomic force microscopy data we illustrate the important difference between elasticity and topography of human platelets in relation to the carriage and non-carriage of $\mathrm{A}$ allele of G20210A polymorphism in healthy subjects. The situation in the carriers of A allele of the G20210A polymorphism presents with the features of pathology, although in a silent state.

Table 2. Topography of platelets from healthy controls non-carriers and carriers of A allele of G20210A polymorphism

\begin{tabular}{lll}
\hline & $\begin{array}{l}\text { Height* }(\mathbf{n m}) \\
\text { Mean } \pm \text { SD }\end{array}$ & $\begin{array}{l}\left.\text { Area* }^{*} \boldsymbol{\mu m}^{2}\right) \\
\text { Mean } \pm \text { SD }\end{array}$ \\
\hline $\begin{array}{l}\text { Non-carriers of 20210A polymorphism } \\
\text { Carriers of 20210A polymorphism }\end{array}$ & $1036 \pm 383$ & $5.15 \pm 2.9$ \\
$\begin{array}{l}\text { Carriers of 20210A polymorphism in the } \\
\text { presence of } \mathrm{Mg}^{2+} \text { ions }\end{array}$ & $995.2 \pm 230$ & $5.16 \pm 3.0$ \\
\hline
\end{tabular}

*Significant data $\mathrm{p}<0.05$ 
These facts confirm our hypothesis that this thrombophilic polymorphism contributes to the activation of the platelets in its reversible phase, which needs additional small triggering event to facilitate the process to its irreversible phase.

The morphological and mechanical assessment of dynamics of platelet function in carriers and non-carriers of thrombophilic mutation contributes to a better understanding of the mechanism of activation of thrombosis and the possibility of its prevention.

The physiological relevance of platelet membrane changes requires further investigation.

\section{Conclusions}

Platelets isolated from carriers of A allele of prothrombin G20210A polymorphism exhibit elevated level of activity and a higher degree of stiffness at the stage of spreading as compared to non-carriers, similar to an initial reversible stage of platelets activation in hemostasis and thrombosis.

\section{Acknowledgements}

The authors disclose receiving financial support for the research from Medical University Pleven, Project N 20/2015.

\section{References}

1. Hartwig J. Mechanism of actin rearrangements mediating platelet activation. J Cell Biol. 1992;118:1421-42.

2. Rheinlaender J, Vogel S, Seifert J, Schächtele M, Borst $\mathrm{O}$, Lang F, et al. Imaging the elastic modulus of human platelets during thrombininduced activation using scanning ion conductance microscopy. J Thromb Haemost. 2015;113(2):305-11.

3. Parise LV, Smyth SS, Coller BS. Platelet morphology, biochemistry, and function. In: Lichtman MA, Beutler E, Kaushansky K, Kipps TJ, Seligsohn U, Prchal J, editors. Williams Hematology. 7th ed. New York: McGraw-Hill Professional; 2005.p. 1357-408.

4. Pompe T, Glorius S, Bischoff T, Uhlmann I, Kaufmann M, Brenner S, et al. Dissecting the impact of matrix anchorage and elasticity in cell adhesion. Biophys J. 2009;97(8):2154-63.

5. Engler AJ, Sen S, Sweeney HL, Discher DE.
Matrix elasticity directs stem cell lineage specification. Cell. 2006. 126:677-89.

6. McBeath R, Pirone DM, Nelson CM, Bhadriraju $\mathrm{K}$, Chen CS. Cell shape, cytoskeletal tension, and RhoA regulate stem cell lineage commitment. Dev Cell. 2004;6:483-95.

7. Offermanns S. Activation of platelet function through $\mathrm{G}$ protein-coupled receptors. Circ Res. 2006. 99(12):1293-304.

8. Jackson SP, Nesbitt WS, Westein E. Dynamics of platelet thrombus formation. J Thromb Haemost. 2009;7 Suppl 1:17-20. doi: 10.1111/j.15387836.2009.03401.

9. Poort SR, Rosendaal FR, Reitsma PH, Bertina RM. A common genetic variation in the 3'untranslated region of the prothrombin gene is associated with elevated plasma prothrombin levels and an increase in venous thrombosis. Blood. 1996;88(10):3698-703. PubMed PMID: 8916933.

10. Martinelli I, Bucciarelli P, MannucciPM. Thrombotic risk factors: basic pathophysiology. Crit Care Med. 2010;38 (2 Suppl):S3-9. doi:10.1097/CCM.0b013e3181c9cbd9. PubMed PMID: 20083911.

11. Evaluation of Genomic Applications in Practice and Prevention (EGAPP) Working Group. Recommendations from the EGAPP Working Group: routine testing for Factor $\mathrm{V}$ Leiden (R506Q) and prothrombin (20210G $>$ A) mutations in adults with a history of idiopathic venous thromboembolism and their adult family members. Genet Med. 2011;13(1):67-76. doi:10.1097/GIM.0b013e3181fbe46f. PubMed PMID: 21150787.

12. Franz CM, Puech P-H. Atomic Force Microscopy: A versatile tool for studying cell morphology, adhesion and mechanics. Cell Mol Bioeng. 2008;1(4):289-300. doi: 10.1007/s12195-0080037-3.

13. Lee IS, Marchant RE. Force measurements on platelet surfaces with high spatial resolution under physiological conditions. Colloids Surf B Biointerfaces. 2000;19(4):357-65.

14. Ortega JE, Barrón-González MP, Gracia-Pinilla MA, Pérez E, López-Aldrete A, Menchaca J-L. Biological samples observed in vitro by Atomic Force Microscopy: Morphology and Elastic Properties. In: Méndez-Vilas A, editor. Microscopy: advances in scientific research and education. Badajoz: Formatex Research Center; 2014.

15. Komsa-Penkova R, Kovacheva-Kotseva K, Angelova S, Savov A, Simeonova M. [Selected methods of DNA analysis and clinical applications]. Pleven: VMI-Pleven; 2004. p. 1628. Bulgarian.

16. Kwok S, Higuchi R. Avoiding false-positives with PCR. Nature. 1989;339:237-8.

17. Dhurat R, Sukesh MS. Principles and methods of 
preparation of platelet-rich plasma: A review and author's perspective. J Cutan Aesthet Surg. 2014;7(4):189-97. doi:10.4103/09742077.150734 .

18. Radmacher M, Tillamnn RW, Fritz M, Gaub HE. From molecules to cells: imaging soft samples with the atomic force microscope. Science. 1992;257:1900-5. doi: 10.1126/science.1411505.

19. Kuznetsova TG, Starodubtseva MN, Yegorenkov NI, Chizhik SA, Zhdanov RI. Atomic force microscopy probing of cell elasticity. Micron. 2007;38(8):824-33.

20. Digital Instruments/Veeco Metrology Group. NanoScope Command Reference Manual Version 5.12 Revision B. Digital Instruments/Veeco Metrology Group Inc.; 2001.

21. Domke J, Radmacher M. Measuring the elastic properties of thin polymer films with the Atomic Force Microscope. Langmuir. 1998;14:3320-25.
22. Starodubtseva M, Chizhik S, Yegorenkov N, Nikitina I, Drozd E. Study of the mechanical properties of single cells as biocomposites by atomic force microscopy. In: Méndez-Vilas A, Díaz J, editors. Microscopy: science, technology, applications and education. Badajoz: Formatex; 2010.

23. Du Plooy JN, Buys A, Duim W, Pretorius E. Comparison of platelet ultrastructure and elastic properties in thrombo-embolic ischemic stroke and smoking using atomic force and scanning electron microscopy. PLoS One. 2013;8(7):e69774.

24. van Rooy M-J, Duim W, Ehlers R, Buys AV, Pretorius E. Platelet hyperactivity and fibrin clot structure in transient ischemic attack individuals in the presence of metabolic syndrome: a microscopy and thromboelastography study. Cardiovasc Diabetol. 2015;14:86. doi: 10.1186/s12933-0150249-5. 